\title{
DMSP biosynthesis by an animal and its role in coral thermal stress response
}

\author{
Jean-Baptiste Raina ${ }^{1,2,3}$, Dianne M. Tapiolas ${ }^{2}$, Sylvain Forêt ${ }^{3,4}$, Adrian Lutz ${ }^{2,3,5}$, David Abrego ${ }^{2} \dagger$, Janja Ceh ${ }^{6}$, François O. Seneca ${ }^{1,2} \dagger$, \\ Peta L. Clode ${ }^{7,8}$, David G. Bourne ${ }^{2}$, Bette L. Willis ${ }^{1,3} \&$ Cherie A. Motti ${ }^{2}$
}

Globally, reef-building corals are the most prolific producers of dimethylsulphoniopropionate (DMSP) ${ }^{1,2}$, a central molecule in the marine sulphur cycle and precursor of the climate-active gas dimethylsulphide ${ }^{3,4}$. At present, DMSP production by corals is attributed entirely to their algal endosymbiont, Symbiodinium ${ }^{2}$. Combining chemical, genomic and molecular approaches, we show that coral juveniles produce DMSP in the absence of algal symbionts. DMSP levels increased up to $54 \%$ over time in newly settled coral juveniles lacking algal endosymbionts, and further increases, up to $76 \%$, were recorded when juveniles were subjected to thermal stress. We uncovered coral orthologues of two algal genes recently identified in DMSP biosynthesis, strongly indicating that corals possess the enzymatic machinery necessary for DMSP production. Our results overturn the paradigm that photosynthetic organisms are the sole biological source of DMSP, and highlight the double jeopardy represented by worldwide declining coral cover, as the potential to alleviate thermal stress through coral-produced DMSP declines correspondingly.

It is widely accepted that the production of dimethylsulphoniopropionate (DMSP), a central molecule in the marine sulphur cycle, is restricted to marine algae and a few species of intertidal plants ${ }^{5}$. Marine bacteria subsequently use DMSP as a source of sulphur and carbon and can metabolize this compound into the volatile gas dimethylsulphide $(D M S)^{6}$, by which the largest natural flux of sulphur enters the atmosphere where it exerts considerable influence on atmospheric chemistry ${ }^{7}$. Despite recent controversy regarding the impact of DMS emissions on global climate ${ }^{8}$, DMS is probably involved in local climate regulation through its oxidation into aerosol particles that induce the formation of clouds and increase their reflectivity, thereby reducing light levels and water temperatures in the marine environment ${ }^{3,4}$.

Concentrations of DMSP and DMS found in reef-building corals are among the highest recorded in the environment ${ }^{1,2}$, but it has been assumed that DMSP production derives solely from the coral's endosymbiotic microalgae Symbiodinium. Evidence that the total amounts of DMSP recorded in corals are consistently higher than levels present in Symbiodinium cells alone $e^{9,10}$ raises the possibility of a cryptic source of DMSP in reef-building corals. A clear understanding of the sources of DMSP on reefs and the possible effects that global warming may have on DMSP production is paramount, given the influence that coralreef-derived sulphur emissions may have on local climates ${ }^{11}$. Corals in the genus Acropora are the most abundant reef-building organisms in the Indo-Pacific region ${ }^{12}$ and, as broadcast spawners, they acquire Symbiodinium from their surrounding environment after larval development. The Symbiodinium-free larvae of this genus provide a unique opportunity to investigate Symbiodinium-independent production of DMSP in corals. Results presented here demonstrate that coral hosts (kingdom: Animalia) are capable of biosynthesizing DMSP in high concentrations in the absence of symbiotic microalgae, refuting the current paradigm that photosynthetic organism are the only DMSP sources in the environment.

DMSP levels were quantified in juveniles lacking photosynthetic symbionts for two common coral species, Acropora millepora and A. tenuis, using nuclear magnetic resonance (NMR) spectroscopy ${ }^{13}$. Juveniles were raised in the dark in $0.2-\mu \mathrm{m}$-filtered seawater to ensure they remained algae-free, and the absence of any photosynthetic organisms in these juveniles was confirmed using five different DNA markers, ranging from Symbiodinium-specific to universal 23S rRNA plastids primers, targeting all eukaryotic algae and cyanobacteria. A lack of any detectable amplification was observed for all markers (Extended Data Tables 1 and 5). Despite the complete absence of any photosynthetic microalgae, high concentrations of DMSP, two orders of magnitude greater than concentrations reported for benthic algae from the Great Barrier Reef ${ }^{2}$, were recorded in all coral juvenile samples (Fig. 1). Repeated sampling over a 6-day period after larval settlement revealed that the initially high DMSP concentrations in juveniles increased significantly over time; specifically, DMSP increased by $44 \%$ (that is, $1.1 \mathrm{nmol} \mathrm{mm} \mathrm{mm}^{-2}$ ) in $A$. millepora and by $54 \%$ (that is, $1.7 \mathrm{nmol} \mathrm{mm}^{-2}$ ) in A. tenuis (ANOVA, $n=6, P<0.005$; Fig. 1 and Extended Data Table 2). These results demonstrate unambiguously that the DMSP levels measured were not inherited from parent colonies but instead were produced by coral juveniles growing in the absence of photosynthetic symbionts.

Increases in DMSP concentrations over time were even more pronounced when coral juveniles experienced thermal stress $\left(32^{\circ} \mathrm{C}\right)$, with A. tenuis and A. millepora exhibiting $65 \%$ and $76 \%$ increases over the 6-day experimental period, respectively (ANOVA, $n=6, P<0.005$; Fig. 1 and Extended Data Table 2). Conversely, concentrations of the DMSP breakdown product acrylate decreased in both species, with thermally stressed juveniles containing 33\% (A. millepora) and $61 \%$ (A. tenuis) less acrylate after 6 days than juveniles at ambient temperature (Fig. 1c, d). Similar declines in acrylate in marine algae subjected to stressful conditions ${ }^{14}$ have been related to its antioxidant properties; acrylate and DMS are both extremely efficient scavengers of hydroxyl radicals and other reactive oxygen species (ROS) ${ }^{14}$. During thermal stress, the production of ROS by coral mitochondria (and Symbiodinium, when present) increases, damaging coral cells ${ }^{15}$. The observed decrease in acrylate concentrations in thermally stressed coral juveniles probably reflects its involvement in ROS detoxification, implicating DMSP and its breakdown products as functionally important in coral stress responses.

Further experimental studies involving adult corals, the building blocks of coral reefs and the most ecologically relevant life history stage in terms of DMSP production, confirm the importance of this

AIMS@JCU, and School of Marine and Tropical Biology, James Cook University, Townsville, Queensland 4811, Australia. ${ }^{2}$ Australian Institute of Marine Science, PMB3, Townsville MC, Townsville,

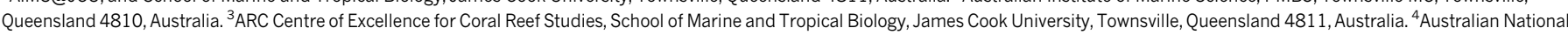

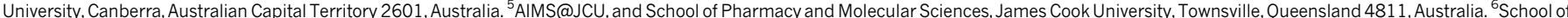

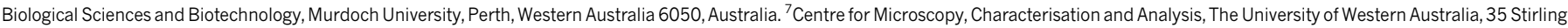

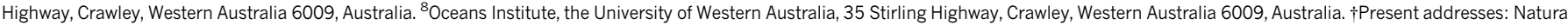

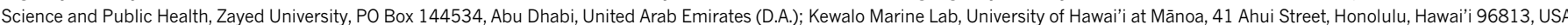
(F.O.S.) 

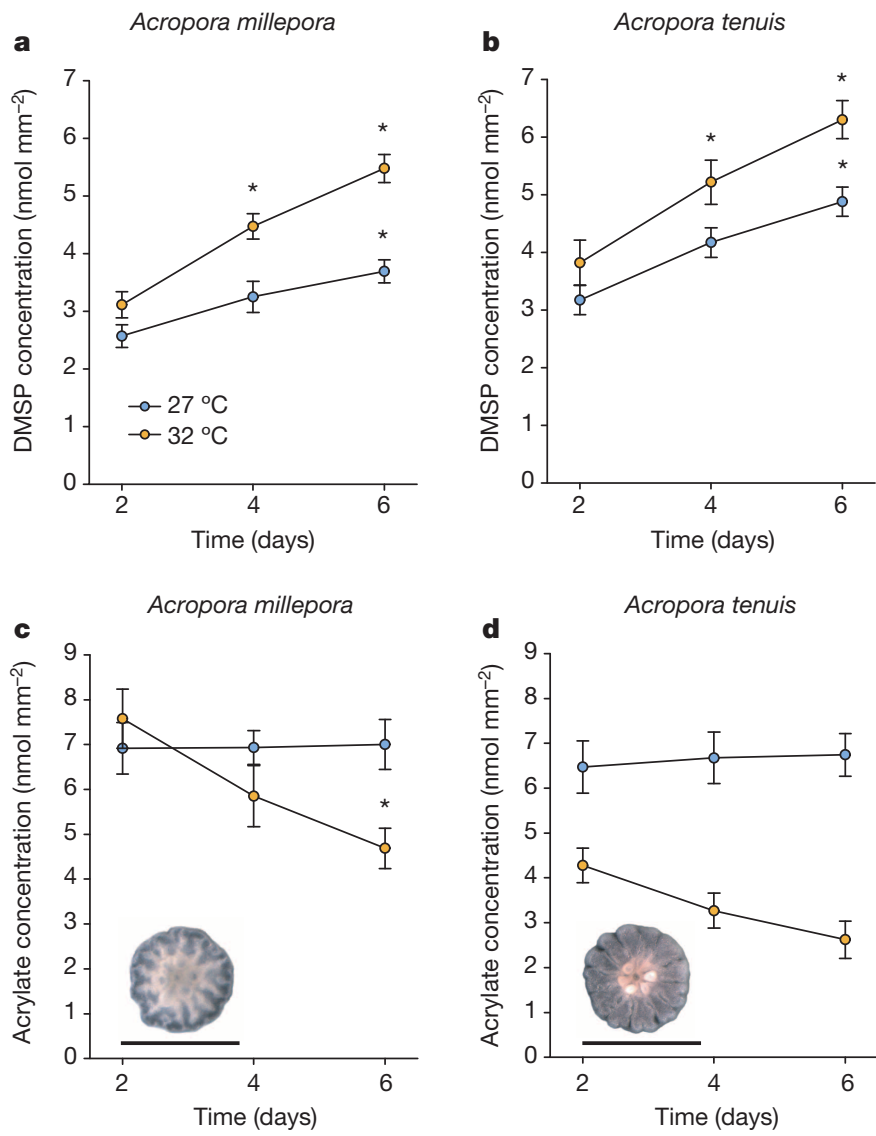

Figure $1 \mid$ Changes in DMSP and acrylate concentrations (mean \pm s.e.) in coral juveniles lacking photosynthetic symbionts $(n=6 ; 40$ juveniles per replicate) through a 6-day period after coral settlement. a, b, Patterns are compared for two thermal regimes: ambient $\left(27^{\circ} \mathrm{C}\right.$, blue) and thermal stress ( $32{ }^{\circ} \mathrm{C}$, orange), and for the coral species Acropora millepora (a) and Acropora tenuis $(\mathbf{b})$. DMSP concentrations increase significantly through time in the juveniles exposed to ambient temperature (ANOVA simple main effect test, $F_{2,20}=6.30, * P<0.01$ for A. millepora and $F_{2,20}=7.51,{ }^{*} P<0.005$ for A. tenuis). Furthermore, DMSP concentrations in coral juveniles exposed to elevated temperature $\left(32^{\circ} \mathrm{C}\right)$ for 6 days were significantly higher than controls kept at ambient temperature $\left(27^{\circ} \mathrm{C}\right)$ (simple main effect test, $F_{1,10}=27.68$, ${ }^{*} P<0.0005$ for A. millepora and $F_{1,10}=10.44,{ }^{*} P<0.01$ for A. tenuis). c, d, Conversely, acrylate concentrations decreased significantly in juveniles of the corals $A$. millepora $(\mathbf{c})$ and $A$. tenuis $(\mathbf{d})$ when exposed to elevated temperature (simple main effect test, $F_{1,10}=5.58, * P<0.05$ for $A$. millepora and $F_{1,10}=61.68,{ }^{*} P<0.0005$ for $A$. tenuis). Scale bar, $1 \mathrm{~mm}$.

compound in coral stress responses and the production of high concentrations of DMSP by the coral host. Colonies of $A$. millepora exposed to $32{ }^{\circ} \mathrm{C}$ for 10 days showed an $84 \%$ reduction in their Symbiodinium cell densities (Extended Data Fig. 1a and Fig. 2a-c), thus photosynthetic symbionts were unlikely to contribute significantly to DMSP production. Furthermore, transmission electron microscopy showed that $100 \%$ of the remaining Symbiodinium cells examined within coral tissues ( $n=272$ cells) were structurally compromised (Extended Data Fig. 2). In particular, thylakoid membranes within chloroplasts were completely disrupted and general cell structure was disordered (Extended Data Fig. 2), characteristics typical of advanced necrosis ${ }^{16}$. Consistent with these observations of dysfunctional cell structures, pulse amplitude modulation (PAM) fluorometry measurements confirmed significant reductions in their photochemical efficiency (ANOVA, $n=12$, $P<0.005$; Extended Data Fig. 1b and Extended Data Table 3). In further support of our conclusion that Symbiodinium were not contributing significantly to DMSP production, previous experiments on Symbiodinium cultures have shown that DMSP content per cell volume decreases under thermal stress ${ }^{17}$.
Despite the severe degradation and depletion of algal symbionts from coral tissues, thermally stressed corals contained $68 \%$ more DMSP (that is, $9 \mathrm{nmol} \mathrm{mm}^{-2}$ ) and concordantly $36 \%$ less acrylate than control colonies (Fig. 2). These results are in close accordance with those we found for coral juveniles. Taken together, our results provide conclusive evidence that the observed increases in DMSP concentrations in thermally stressed corals cannot be attributed to the activity of Symbiodinium cells. This implies that DMSP production is not restricted to juvenile life stages, but also occurs at high levels in adult reef-building corals subjected to thermal stress. In addition to its antioxidant role, DMSP is involved in several key cellular and ecological processes in reef-building corals, notably as an osmoprotectant during salinity fluctuations, but also as a signal molecule attracting specific bacteria which form microbial communities that are integrally associated with corals and underpin their health ${ }^{18}$. The multiple functions of this molecule might explain the ecological advantage of producing it directly.

To further support our conclusion that DMSP is produced by the coral host, we examined potential molecular mechanisms underlying their DMSP biosynthetic capabilities. In some marine algae, DMSP is produced from methionine via a pathway that involves the successive action of four different enzymes ${ }^{19}$, but until recently, very little was known about genes involved in its biosynthesis. A recent study identified candidate genes for each of the four steps of the biosynthesis pathway in the diatom Fragilariopsis cylindrus ${ }^{20}$. We searched for potential orthologues of these genes in the comprehensive molecular resources available for two coral species, the $A$. millepora transcriptome ${ }^{21}$ and the Acropora digitifera genome ${ }^{22}$, and found that two genes identified in diatoms have clear orthologues in corals. These genes encode a NADPHreductase and an AdoMet-dependant methyltransferase, which mediate the second and third steps of the biosynthesis process, respectively (Fig. 3a). The orthologous relationship between the corals' and diatom's genes is supported by best reciprocal blast hits and their mapping to the same OrthoMCL clusters ${ }^{23}$ (Extended Data Table 4). We also identified two Symbiodinium sequences (from a comprehensive transcriptome assembly $^{24}$ ) belonging to the same OrthoMCL clusters as the reductase and methyltransferase identified in diatoms and corals (Extended Data Table 4). This indicates that the function of these enzymes in DMSP biosynthesis may be conserved between diatoms, alveolates, green plants and corals.

Results derived from the A. millepora transcriptome ${ }^{21}$ enabled us to estimate the level of expression of these two genes throughout five life stages, from embryos to adults. We found the gene encoding the reductase, a reversible step in the DMSP biosynthesis process ${ }^{5}$, to be highly expressed throughout all life-history stages (Fig. 3b). The phylogenetic distribution of its OrthoMCL cluster revealed 45 orthologues spread throughout all kingdoms (Extended Data Fig. 3), in line with the widespread presence of this enzyme among plants that do not produce $\mathrm{DMSP}^{5}$. In contrast, the methyltransferase mediates a nonreversible step regulating intracellular DMSP level $\mathrm{s}^{25}$ and is believed to be specific to this pathway ${ }^{5}$. The gene encoding the methyltransferase was highly expressed in early coral life stages, but its expression decreased after settlement and remained relatively low in adult corals (Fig. 3c). This expression pattern correlates with the establishment of symbiosis with DMSP-producing Symbiodinium around the time of settlement. The OrthoMCL cluster corresponding to the methyltransferase has an unusually sparse phyletic pattern with only nine orthologues, including seven in photosynthetic organisms and two in other eukaryotes (Extended Data Fig. 3), indicating that corals are likely to be the exception, rather than the rule, in terms of DMSP production by marine invertebrates harbouring photosynthetic symbionts ${ }^{26}$.

We show that the unparalleled levels of DMSP present in reefbuilding corals are not attributable solely to their endosymbiotic algae; instead, a significant fraction is produced by the coral animal. DMSP concentrations measured in coral juveniles devoid of symbiotic algae represented approximately half of those present in symbiont-bearing adult corals, indicating that the coral animal contributes extensively to 

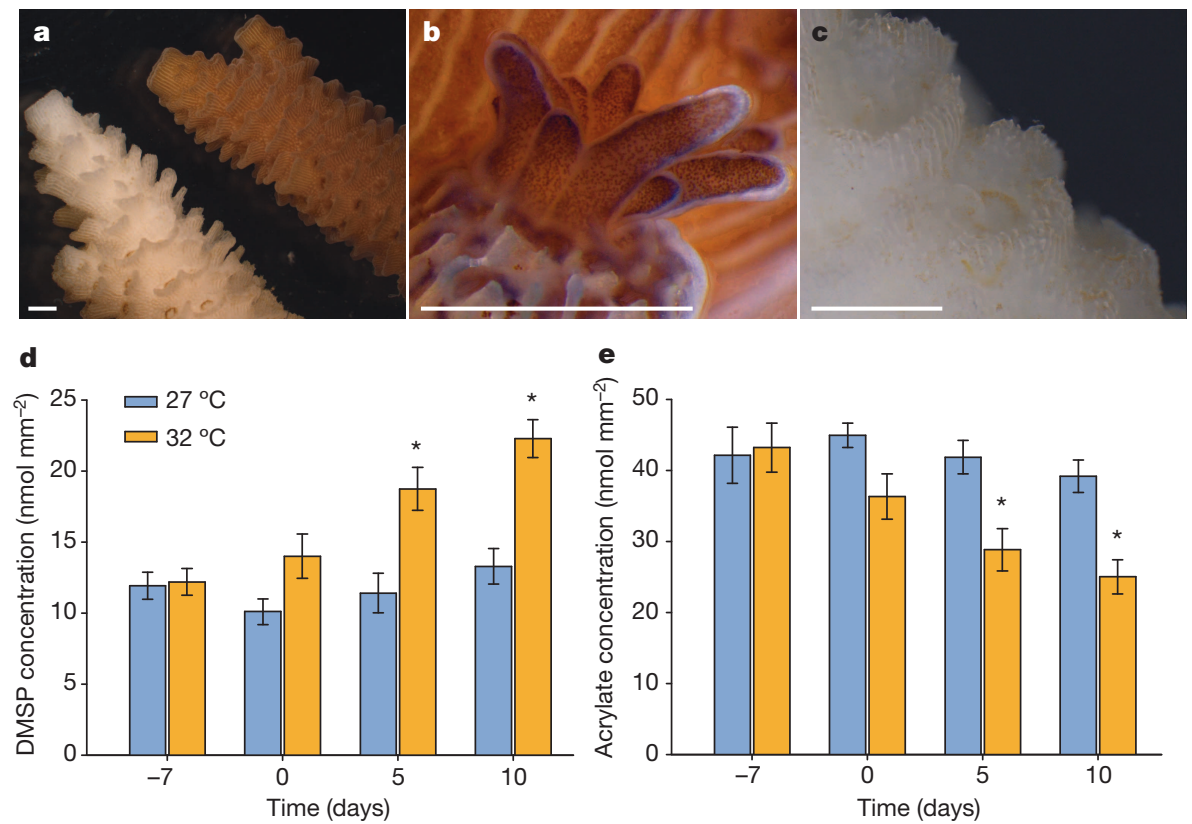

Figure $2 \mid$ Effects of thermal stress on adult colonies of the coral Acropora millepora.

Temperature was raised gradually over 7 days to $32{ }^{\circ} \mathrm{C}$, mimicking a realistic thermal stress scenario, therefore thermal stress commenced on day 0 . The total duration of the experiment was 17 days. a, Micrograph of representative coral nubbins showing visual differences in the density of Symbiodinium cells present in the tissues of A. millepora maintained under control $\left(27^{\circ} \mathrm{C}\right.$, brown, right) or thermal stress $\left(32^{\circ} \mathrm{C}\right.$, white, left) conditions for 10 days. b, c, Higher magnification micrographs of coral polyps showing visual differences in tissue colour as intracellular Symbiodinium densities decline between $27^{\circ} \mathrm{C}$ (b) and $32^{\circ} \mathrm{C}$ (c) (scale bars, $\left.1 \mathrm{~mm}\right)$. d, Changes in DMSP concentration (mean \pm s.e.) in adult corals $(n=12)$ exposed to control $\left(27^{\circ} \mathrm{C}\right)$ and thermal stress $\left(32^{\circ} \mathrm{C}\right)$ treatments (ANOVA simple main effect test, $\left.F_{1,22}=10.79, * P<0.005\right)$.

e, Corresponding changes in acrylate concentration (mean \pm s.e.) in adult corals $(n=12)$ exposed to control $\left(27^{\circ} \mathrm{C}\right)$ and thermal stress $\left(32^{\circ} \mathrm{C}\right.$ ) treatments (ANOVA simple main effect test, $\left.F_{1,22}=8.4, * P<0.01\right)$. the DMSP pool produced on coral reefs. Surveys over Australia identified the Great Barrier Reef as a significant hotspot for the emission of sulphur aerosol particles ${ }^{27,28}$. The Great Barrier Reef is the largest biological structure on the planet and the release of these particles along its 2,600-km length could constitute a major source of cloud condensation nuclei. Coral-reef-derived sulphur aerosol emission might therefore have a central role in cloud formation in areas of the world with high coral densities, such as the Great Barrier Reef and the Coral

a

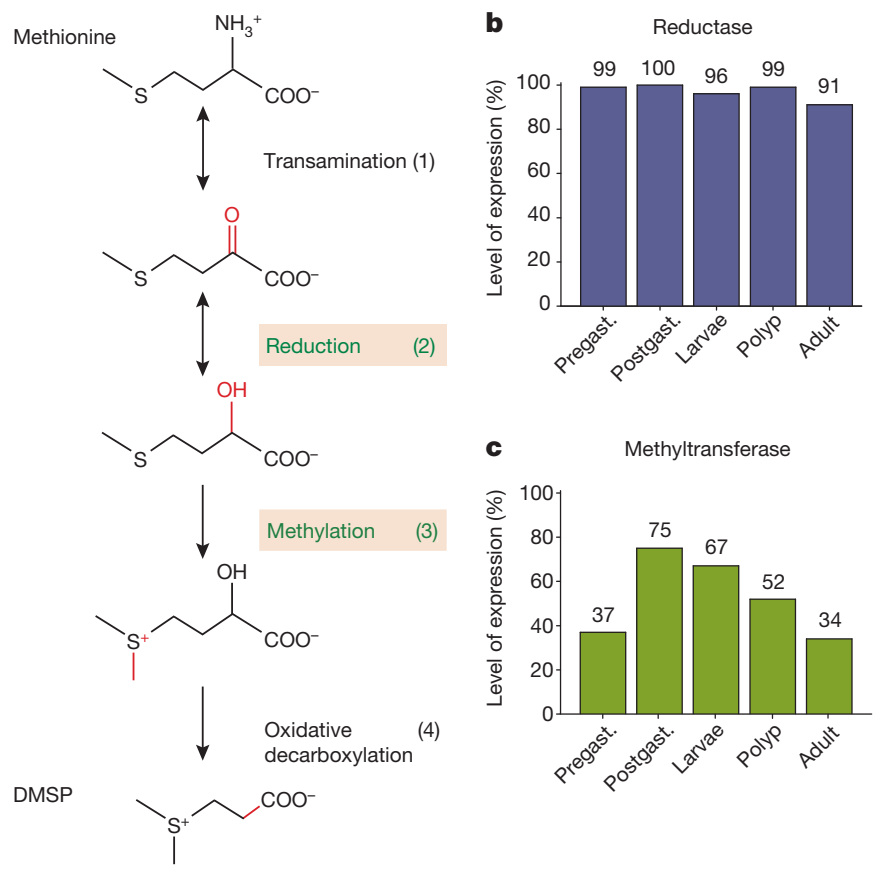

Figure 3 Putative DMSP biosynthesis pathway and gene expression of coral orthologues. a, Pathway of DMSP biosynthesis present in marine algae ${ }^{19}$ (the first two steps are reversible). The proposed diatom genes encoding the second and third steps (in green) have orthologues in Acropora millepora and Acropora digitifera genomes (see Extended Data Table 4). b, c, Gene expression percentiles of the two putative genes involved in DMSP biosynthesis in A. millepora through five coral life stages, from embryos (pregast., pregastrula; postgast., postgastrula) to adults, based on transcriptomic data from ref. 21.
Triangle ${ }^{11,29}$. Considering declining trends in coral cover ${ }^{30}$ and predicted increases in coral mortality worldwide caused by anthropogenic stressors, the associated decline in sulphur aerosol production from coral reefs may further destabilize local climate regulation and accelerate degradation of this globally important and diverse ecosystem.

\section{METHODS SUMMARY}

Coral juvenile sampling. Coral larvae were raised for 12 days in $0.5-\mu \mathrm{m}$-filtered seawater (FSW), subsequently washed three times in $0.2-\mu \mathrm{m}$ FSW and settled in sterile 6-well plates (8 plates per species, 40 larvae per well; each well filled with $10 \mathrm{ml}$ of $0.2-\mu \mathrm{m} \mathrm{FSW}$ ). Eight hours after settlement, the plates were separated between two treatments: 4 plates per species were incubated at $27^{\circ} \mathrm{C}$ (control temperature), and the other 4 plates were ramped to $32^{\circ} \mathrm{C}$ over $5 \mathrm{~h}$ (thermal stress treatment). All plates were kept in the dark (to prevent the growth of potential photosynthetic organisms) and 6 random wells were sampled every 2 days.

DNA extractions and PCR amplification. At each time point, the contents of two wells were scraped into a 2 -ml tube using a scalpel blade, snap frozen with liquid nitrogen, and used for total DNA extraction. Multiple sets of primers were subsequently used to target the Symbiodinium, coral and other photosynthetic organisms (Extended Data Tables 1 and 5).

Identification of candidate genes. Orthology between coral, Symbiodinium and diatom genes was inferred based on best reciprocal BLAST hits. Orthologues in other species were identified using release 5 (March 2011) of the OrthoMCL database ${ }^{3}$. Database for A. digitifera genome: http://marinegenomics.oist.jp/genomes/ download?project_id $=3$ annotation version 1.0. Database for $A$. millepora transcriptome: NCBI Transcriptome Shotgun Assembly (TSA) ${ }^{21}$.

Adult thermal stress experiment. Ten coral colonies were split to give a total of 24 fragments, each comprising approximately 25 branches (nubbins). Fragments were arranged in eight indoor tanks in a randomized block design. After 2 weeks of acclimatization, the temperature in four tanks was ramped-up slowly to $32^{\circ} \mathrm{C}$, whereas the other four tanks were maintained at $27^{\circ} \mathrm{C}$. Each temperature treatment contained a total of 12 fragments.

qNMR analysis. Adult and juvenile corals were extracted and analysed in accordance with the qNMR technique described previously ${ }^{13}$.

Online Content Any additional Methods, Extended Data display items and Source Data are available in the online version of the paper; references unique to these sections appear only in the online paper.

Received 31 July; accepted 18 September 2013.

Published online 23 October 2013.

1. Broadbent, A. D. \& Jones, G. B. DMS and DMSP in mucus ropes, coral mucus, surface films and sediment pore waters from coral reefs in the Great Barrier Reef. Mar. Freshw. Res. 55, 849-855 (2004).

2. Broadbent, A. D., Jones, G. B. \& Jones, R. J. DMSP in corals and benthic algae from the Great Barrier Reef. Estuar. Coast. Shelf Sci. 55, 547-555 (2002). 
3. Ayers, G. P. \& Gras, J. L. Seasonal relationship between cloud condensation nuclei and aerosol methanesulphonate in marine air. Nature 353, 834-835 (1991).

4. Vallina, S. M. \& Simo, R. Strong relationship between DMS and the solar radiation dose over the global surface ocean. Science 315, 506-508 (2007).

5. Stefels, J. Physiological aspects of the production and conversion of DMSP in marine algae and higher plants. J. Sea Res. 43, 183-197 (2000).

6. Todd, J. D. et al. Structural and regulatory genes required to make the gas dimethylsulfide in bacteria. Science 315, 666-669 (2007).

7. Sievert, S. M., Kiene, R. P. \& Schulz-Vogt, H. N. The sulfur cycle. Oceanography 20, 117-123 (2007).

8. Quinn, P. K. \& Bates, T. S. The case against climate regulation via oceanic phytoplankton sulphur emissions. Nature 480, 51-56 (2011).

9. Yost, D. M., Jones, R., Rowe, C. L. \& Mitchelmore, C. L. Quantification of total and particulate dimethylsulfoniopropionate (DMSP) in five Bermudian coral species across a depth gradient. Coral Reefs 31, 561-570 (2012).

10. Yost, D. M. \& Mitchelmore, C. L. Determination of total and particulate dimethylsulfoniopropionate (DMSP) concentrations in four scleractinian coral species: a comparison of methods. J. Exp. Mar. Biol. Ecol. 395, 72-79 (2010).

11. Fischer, E. \& Jones, G. B. Atmospheric dimethylsulphide production from corals in the Great Barrier Reef and links to solar radiation, climate and coral bleaching. Biogeochemistry 110, 31-46 (2012).

12. Veron, J. E. N. Corals of the World Vol. 1-3 (Australian Institute of Marine Science, 2000).

13. Tapiolas, D. M., Raina, J. B., Lutz, A., Willis, B. L. \& Motti, C. A. Direct measurement of dimethysulfoniopropionate (DMSP) in reef-building corals using quantitative nuclear magnetic resonance (qNMR) spectroscopy. J. Exp. Mar. Biol. Ecol. 443, 85-89 (2013).

14. Sunda, W., Keiber, D. J., Kiene, R. P. \& Hunstsman, S. An antioxidant function for DMSP and DMS in marine algae. Nature 418, 317-320 (2002).

15. Lesser, M.P. in Coral Reefs: An Ecosystem in Transition (eds Dubinsky, Z. \& Stambler N.) 405-419 (Springer, 2011).

16. Strychar, K. B., Sammarco, P. W. \& Piva, T. J. Apoptotic and necrotic stages of Symbiodinium (Dinophyceae) cell death activity: bleaching of soft and scleractinian corals. Phycologia 43, 768-777 (2004).

17. McLenon, A. L. \& DiTullio, G. R. Effect of increased temperature on dimethylsulfoniopropionate (DMSP) concentration and methionine synthase activity in Symbiodinium microadriaticum. Biogeochemistry 110, 17-29 (2012).

18. Raina, J. B., Dinsdale, E. A., Willis, B. L. \& Bourne, D. G. Do the organic sulfur compounds DMSP and DMS drive coral microbial associations? Trends Microbiol. 18, 101-108 (2010).

19. Gage, D. A. et al. A new route for synthesis of dimethylsulfoniopropionate in marine algae. Nature 387, 891-894 (1997).

20. Lyon, B. R., Lee, P. A., Bennett, J. M., DiTullio, G. R. \& Janech, M. G. Proteomic analysis of a sea-ice diatom: salinity acclimation provides new insight into the dimethylsulfoniopropionate production pathway. Plant Physiol. 157, 1926-1941 (2011).
21. Moya, A. et al. Whole transcriptome analysis of the coral Acropora millepora reveals complex responses to $\mathrm{CO}_{2}$-driven acidification during the initiation of calcification. Mol. Ecol. 21, 2440-2454 (2012).

22. Shinzato, C. et al. Using the Acropora digitifera genome to understand coral response to environmental change. Nature 476, 320-323 (2011).

23. Chen, F., Mackey, A. J., Vermunt, J. K. \& Roos, D. S. Assessing performance of orthology detection strategies applied to eukaryotic genomes. PLOS ONE 2, e383 (2007).

24. Bayer, T. et al. Symbiodinium transcriptomes: genome insights into the dinoflagellate symbionts of reef-building corals. PLOS ONE 7, e35269 (2012).

25. Ito, T., Asano, Y., Tanaka, Y. \& Takabe, T. Regulation of biosynthesis of dimethylsulfoniopropionate and its uptake in sterile mutant of Ulva pertusa (Chlorophyta). J. Phycol. 47, 517-523 (2011).

26. Van Alstyne, K. L., Dominique, V. J. \& Muller-Parker, G. Is dimethylsulfoniopropionate (DMSP) produced by the symbionts or the host in an anemone-zooxanthellae symbiosis? Coral Reefs 28, 167-176 (2009).

27. Bigg, E. K. \& Turvey, D. E. Sources of atmospheric particles over Australia. Atmos. Environ. 12, 1643-1655 (1978)

28. Modini, R. L. et al. New particle formation and growth at a remote, sub-tropical coastal location. Atmos. Chem. Phys. 9, 7607-7621 (2009).

29. Leahy, S. M., Kingsford, M. J. \& Steinberg, C. R. Do clouds save the Great Barrier Reef? Satellite imagery elucidates the cloud-SST relationship at the local scale. PLOS ONE 8, e70400 (2013).

30. De'ath, G., Fabricius, K. E., Sweatman, H. \& Puotinen, M. The 27-year decline of coral cover on the Great Barrier Reef and its causes. Proc. Natl Acad. Sci. USA 109 , 17995-17999 (2012).

Acknowledgements The authors would like to thank D. Yellowlees, R. Stocker, M. Garren, A. Johnston, W. Dunlap, H. Harrison, P. Warner and E. Botté for valuable comments on the manuscript. We specially thank K. Ritchie for her advice and encouragement. We also thank J. Hicks, P. Barron (Bruker Biospin), A. Negri, T. Harder, J. Tebben, M. Logan and J. Pollock for their assistance. This work was supported by the AMMRF Centre for Microscopy, Characterisation and Analysis (UWA), the ARC Centre of Excellence for Coral Reef Studies and AIMS.

Author Contributions J.-B.R. and A.L. designed the experiments. J.-B.R., C.A.M., D.A. and D.M.T. performed the juvenile experiment. J.-B.R., C.A.M., A.L., F.O.S. and D.M.T. performed the adult experiment. J.-B.R., P.L.C., C.A.M. and D.M.T. analysed the results. S.F. and J.-B.R. identified the candidate genes. J.-B.R. and B.L.W. wrote the manuscript. All authors edited the manuscript before submission.

Author Information Reprints and permissions information is available at www.nature.com/reprints. The authors declare no competing financial interests. Readers are welcome to comment on the online version of the paper. Correspondence and requests for materials should be addressed to J.-B.R. (j.raina@aims.gov.au). 


\section{METHODS}

\section{Adult corals}

Thermal stress experiment. Acropora millepora colonies $(n=10)$ were collected from Pelorus Island, Great Barrier Reef, Australia $\left(18^{\circ} 33^{\prime} \mathrm{S} / 146^{\circ} 29^{\prime} \mathrm{E}\right)$ and transferred to the Australian Institute of Marine Science. Coral colonies were fragmented to give a total of 24 fragments, each comprising approximately 25 branches (nubbins). Fragments were arranged in eight indoor tanks in a randomized block design, resulting in the allocation of 12 coral fragments to each of the control and thermal stress temperature treatments $\left(27^{\circ} \mathrm{C}\right.$ and $32^{\circ} \mathrm{C}$, respectively). All tanks were continuously supplied with fresh $1-\mu \mathrm{m}$ filtered seawater (FSW), which was maintained at $27^{\circ} \mathrm{C}\left( \pm 0.1^{\circ} \mathrm{C}\right)$ via computer control using a flow-through system at a rate of $1.51 \mathrm{~min}^{-1}$. Ultraviolet-filtered lights were mounted above each tank and provided an average underwater light intensity of $350 \mu \mathrm{E}$ over a $12 / 12 \mathrm{~h}$ light/ dark cycle ( $400 \mathrm{~W}$ metal halide lamps, BLV), typical of light intensities recorded at the collection site. The fragments were acclimatized for 2 weeks before starting the experiment. Seawater temperatures in four tanks were slowly and continuously ramped to $32^{\circ} \mathrm{C}\left( \pm 0.05^{\circ} \mathrm{C}\right)$ over a 7 -day period, via computer control, while the remaining four control tanks were maintained at $27^{\circ} \mathrm{C}$ for the entire duration of the experiment.

Coral nubbins were sampled four times during the experiment: before any temperature changes when both treatments were at $27^{\circ} \mathrm{C}(t=-7)$; once the $32{ }^{\circ} \mathrm{C}$ target temperature had been reached in the thermal stress treatment $(t=0)$; after 5 days at $32^{\circ} \mathrm{C}$, when the first physiological effects of temperature stress were visible $(t=5)$; and after 10 days at $32{ }^{\circ} \mathrm{C}$ when all colonies in the $32^{\circ} \mathrm{C}$ treatment were completely bleached $(t=10)$. At each time point, one coral nubbin (approximately $50 \mathrm{~mm}$ in length) was collected from each coral fragment $(n=24)$ and immediately transferred to a tube containing $2 \mathrm{ml}$ of HPLC-grade methanol for quantitative nuclear magnetic resonance (qNMR) analysis. Another coral nubbin was collected from each coral fragment $(n=24)$ to evaluate Symbiodinium densities. In addition, one coral nubbin was collected at each time point from four different coral fragments, transferred directly into fixative $(1.25 \%$ glutaraldehyde $+0.5 \%$ paraformaldehyde in $0.2-\mu \mathrm{m} \mathrm{FSW}$ ) and stored at $4{ }^{\circ} \mathrm{C}$ until processed for structural investigations by transmission electron microscopy (TEM).

Quantitative NMR analysis. The coral nubbins were extracted in methanol for $2 \mathrm{~h}$ with sonication followed by a second extraction with an additional $1 \mathrm{ml}$ of HPLC-grade methanol for $10 \mathrm{~min}$. The two extracts were pooled and dried using a vacuum-centrifuge then re-suspended in a mixture of deuterium oxide $\left(\mathrm{D}_{2} \mathrm{O}, \mathrm{D}\right.$ $99.8 \%, 250 \mu \mathrm{l})$ and deuterated methanol $\left(\mathrm{CD}_{3} \mathrm{OD}, \mathrm{D} 99.8 \%, 750 \mu \mathrm{l}\right)$ (Cambridge Isotope Laboratories). A $700 \mu \mathrm{l}$ aliquot of the particulate-free extract was transferred into a 5-mm Norell 509-UP-7 NMR tube (Norell Inc.) and analysed immediately by ${ }^{1} \mathrm{H}$ NMR.

${ }^{1} \mathrm{H}$ NMR spectra were recorded on a Bruker Avance $600 \mathrm{MHz}$ NMR spectrometer with TXI 5-mm probe and quantification performed using the ERETIC method ${ }^{13}$. This technique generates an internal electronic reference signal, calibrated using commercial stock solutions of $4 \mathrm{mM}$ acrylate and DMSP. The concentrations of DMSP and acrylate were determined by integration of their respective signals in a 0.10 p.p.m. window ${ }^{13}$

Symbiodinium densities. Freshly collected coral nubbins were airbrushed $\left(80 \mathrm{lb} \mathrm{in}^{-2}\right)$ in individual plastic bags in $4 \mathrm{ml}$ of $0.2-\mu \mathrm{m}$ FSW. The slurry was homogenized to breakdown aggregates and centrifuged at 3,000 r.c.f. (relative centrifugal force). The supernatant was removed and the pellet re-suspended in $1 \mathrm{ml}$ of $10 \%$ formalin. Homogeneous extracts were placed on a hemocytometer (depth $0.1 \mathrm{~mm}$ ) and Symbiodinium cells were counted under a light microscope (eight technical replicates were averaged per sample).

Symbiodinium genotype. In hospite Symbiodinium populations of each experimental coral fragment were characterized on the basis of sequence differences in the nuclear ribosomal DNA internal transcribed spacer 1 region using singlestrand conformation polymorphism (SSCP) analysis ${ }^{31}$. Total DNA was extracted using a modified protocol ${ }^{32}$. Symbiodinium ITS1 region was amplified with fluorescently labelled Sym ITS1 PCR primers. Genotype was determined using SSCP with known reference samples running alongside experimental samples and scored manually using gel images. All colonies contained only Symbiodinium type C2 (GenBank accession AF380552) SSCP profiles from all samples were single bands identical to the reference).

Surface-area calculation. Coral skeletons remaining after samples were extracted for qNMR analyses and Symbiodinium densities were lyophilized overnight and their surface area determined using a wax dipping technique ${ }^{33}$. The surface area of each individual nubbin was used to normalize the qNMR and Symbiodinium data. Transmission electron microscopy. Fixed coral nubbins were decalcified in a formic acid:fixative mixture (1:3), with the solution changed every $12 \mathrm{~h}$ until complete dissolution of the skeleton. Three individual polyps per sample were postfixed in osmium and subsequently dehydrated with increasing concentrations of ethanol followed by dry acetone. Dehydrated samples were infiltrated in increasing concentrations of Araldite resin before being cured for $24 \mathrm{~h}$ at $60^{\circ} \mathrm{C}$. Longitudinal sections $90-\mathrm{nm}$ thick were collected on copper grids and imaged at $120 \mathrm{kV}$ in a JEOL 2100 TEM

Pulse amplitude modulation (PAM) fluorometry measurements. Photosystem II (PSII) photochemical efficiency was measured with a Diving-PAM (Walz) on three random nubbins per coral fragment. Minimum and maximum fluorescence $\left(F_{\mathrm{O}}\right.$ and $\left.F_{\mathrm{M}}\right)$ were recorded daily, $2 \mathrm{~h}$ before the start of the light cycle. PS II photochemica efficiency was expressed as maximum quantum yields $\left(\left(F_{\mathrm{M}}-F_{\mathrm{O}}\right) / F_{\mathrm{M}}\right)=\left(F_{\mathrm{V}} / F_{\mathrm{M}}\right)$. Data analyses. All data were square root transformed and no significant tank effect was detected for the DMSP, acrylate and PAM fluorometry data (nested ANOVA, $P>0.05$ ) (Statistica 7, Statsoft). The sample size was chosen based on results from a pilot study. Repeated measures ANOVA were carried out on the time series data (data met all assumptions of the test). Simple main effect tests ${ }^{34}$ were used to compare the results between the two temperature treatments, and between temperatures at each time point (Extended Data Table 3). This statistical technique was used to minimize the number of multiple comparisons (focusing only on comparisons of interest), decreasing the likelihood of type I error.

Coral juveniles

Sample collections. Colonies of A. millepora $(n=10)$ and A. tenuis $(n=3)$ were collected from Orpheus Island, Great Barrier Reef, Australia $\left(18^{\circ} 34^{\prime} \mathrm{S} / 146^{\circ} 30^{\prime} \mathrm{E}\right)$ and transferred to the Australian Institute of Marine Science outdoor aquarium facility 4 days before the predicted spawning event in November 2011. One hour before spawning, the colonies were isolated in 701 tanks with $1-\mu \mathrm{m}$ FSW. Gametes were collected from the surface of these tanks and fertilized in separate 70-1 tanks with FSW. After fertilization, embryos were gently rinsed three times by transferring to new containers and were subsequently transferred to 500-l tanks (containing $0.5-\mu \mathrm{m} \mathrm{FSW}$ ) where they were kept through larval development. After 12 days, Symbiodinium-free coral larvae were collected using a $1 \mu \mathrm{m}$ mesh net and washed three times in $0.2-\mu \mathrm{m}$ FSW. Larvae were subsequently settled in sterile 6-well plates (8 plates per species, 40 larvae per well; each well filled with $10 \mathrm{ml}$ of $0.2-\mu \mathrm{m}$ FSW). Eight hours after settlement, the plates were separated between two temperature regimes: 4 plates per species were incubated at $27^{\circ} \mathrm{C}$ (control temperature), and the other 4 plates were ramped to $32{ }^{\circ} \mathrm{C}$ over $5 \mathrm{~h}$ (thermal stress treatment); all plates were maintained in the dark (to prevent the growth of potential photosynthetic organisms). Settled juveniles were incubated at their respective temperature treatments and six random wells were sampled every 2 days. The size of the sampled juveniles was measured using a motorized stereomicroscope (Leica MZ16A, Leica Microsystems); sizes did not vary significantly between day 2 and day 6 with an average size of $0.79 \mathrm{~mm}^{2}( \pm 0.05)$ for A. millepora juveniles and of $0.82 \mathrm{~mm}^{2}( \pm 0.07)$ for $A$. tenuis juveniles.

qNMR analysis. After the required incubation time, seawater was removed from each well with a pipette, and a sterile cotton bud was used to soak up any residual seawater, taking care not to disturb the settled juvenile corals. Juveniles in six wells were extracted by adding $300 \mu \mathrm{l}$ of deuterated methanol $\left(\mathrm{CD}_{3} \mathrm{OD}\right)$ to each well, followed by 30 s of gentle shaking; $200 \mu$ of this extract was transferred into a 3-mm Bruker MATCH NMR tube and analysed immediately. In addition, negative control wells without settled juveniles were extracted following the same procedure. The concentrations of DMSP and acrylate were normalized initially to the number of settled coral juveniles in the respective well. They were then normalized to the averaged surface area of the juveniles (note that juveniles were approximated to perfect circles).

DNA extractions and PCR amplification. At each time point, the contents of two wells were scraped into a $2-\mathrm{ml}$ tube using a scalpel blade, snap frozen with liquid nitrogen, and used for total DNA extraction, according to methods in ref. 35 Multiple sets of primers were subsequently used to target different taxonomic groups: Symbiodinium ${ }^{31}$, coral $^{36}$ and general primers for the algal 23S rDNA plastid $^{37}$ and chloroplast $\mathrm{DNA}^{38}$ (Extended Data Table 1). Furthermore, three other DNA markers were used to target microbes: Bacteria ${ }^{39}$, Archaea $^{40}$ and Fungi ${ }^{41}$ (Extended Data Table 1).

The PCR consisted of $1 \mu \mathrm{l}$ of DNA template (dilution series from 1 to $10^{-5}$ of the original concentrations), $10 \mu \mathrm{l}$ of buffer containing $\mathrm{dNTP}$ and $\mathrm{MgCl}_{2}$ (Bioline), $1.5 \mu \mathrm{l}$ of each primer $(10 \mu \mathrm{M})$, and $0.5 \mu \mathrm{l}$ of Taq polymerase (Bioline), adjusted to a final volume of $50 \mu \mathrm{l}$ with sterile MilliQ water. Amplified PCR products were visualized by electrophoresis on $1 \%$ agarose gel stained with ethidium bromide. Clone libraries construction. PCR products from bacterial 16S ribosomal RNA gene were purified using a QIAquick gel extraction kit (Qiagen) according to the manufacturer's instructions. Purified DNA was ligated into a TOPO-TA cloning vector (Invitrogen) and competent cells were transformed following the manufacturer's instructions. Four samples, derived from the last experimental time point ( 6 days), were analysed (A. millepora at $27^{\circ} \mathrm{C} ; A$. millepora at $32^{\circ} \mathrm{C} ; A$. tenuis at $27^{\circ} \mathrm{C}$; and $A$. tenuis at $32^{\circ} \mathrm{C}$ ). A total of 48 clones were sequenced per sample (Macrogen Inc.) and chimaeric sequences were removed from subsequent analysis. 
The nucleotide sequences obtained have been deposited in GenBank database under the accession numbers (KF619251 to KF619442).

Identification of candidate genes. Orthology between coral and diatom genes was inferred on the basis of best reciprocal BLAST hits ${ }^{42}$. Orthologues in other species were identified using release 5 (March 2011) of the OrthoMCL database ${ }^{23}$. Database for A. digitifera genome: http://marinegenomics.oist.jp/genomes/download?project_id=3 annotation version 1.0; for A. millepora transcriptome: NCBI Transcriptome Shotgun Assembly (TSA) ${ }^{21}$.

Data analyses. Repeated measure ANOVA were performed on the normalized DMSP and acrylate concentrations (data met all assumptions of the test, except the acrylate data from $A$. tenuis that violated sphericity assumption; in that unique case, Greenhouse-Geisser correction was applied to the degrees of freedom). Simple main effect tests ${ }^{34}$ were then used to compare the results from the temperature treatment within species (Extended Data Table 2).

31. van Oppen, M. J. H., Palstra, F. P., Piquet, A. M. T. \& Miller, D. J. Patterns of coraldinoflagellate associations in Acropora: significance of local availability and physiology of Symbiodinium strains and host-symbiont selectivity. Proc. R. Soc. Lond. B 268, 1759-1767 (2001).

32. Wilson, K. et al. Genetic mapping of the black tiger shrimp Penaeusmonodon with amplified fragment length polymorphism. Aquaculture 204, 297-309 (2002).

33. Veal, C. J., Holmes, G., Nunez, M., Hoegh-Guldberg, O. \& Osborn, J. A comparative study of methods for surface area and three dimensional shape measurement of coral skeletons. Limnol. Oceanogr. Methods 8, 241-253 (2010).

34. Quinn, G. P. \& Keough, M. J. Experimental Design and Data Analysis for Biologists (Cambridge Univ. Press, 2002).

35. Bourne, D. \& Munn, C. Diversity of bacteria associated with the coral Pocilloporada micornis from the Great Barrier Reef. Environ. Microbiol. 7, 1162-1174 (2005).

36. Suzuki, G., Hayashibara, T., Shirayama, Y.\& Fukami, H. Evidence of species-specific habitat selectivity of Acropora corals based on identification of new recruits by two molecular markers. Mar. Ecol. Prog. Ser. 355, 149-159 (2008).

37. Sherwood, A. R., Chan, Y. L. \& Presting, G. G. Application of universally amplifying plastid primers to environmental sampling of a stream periphyton community. Mol. Ecol. Res. 8, 1011-1014 (2008).

38. Taberlet, P., Gielly, L., Pautou, G. \& Bouvet, J. Universal primers for amplification of three non-coding regions of chloroplast DNA. Plant Mol. Biol. 17, 1105-1109 (1991).

39. Marchesi,J. R. etal. Design and evaluation of useful bacterium-specific primers that amplify genes coding for 16S rRNA. Appl. Environ. Microbiol. 64, 795-799 (1998).
40. Takai, K. \& Horikoshi, K. Rapid detection and quantification of members of the archaeal community by quantitative PCR using fluorogenic probes. Appl. Environ. Microbiol. 66, 5066-5072 (2000)

41. White, T. J., Bruns, T., Lee, S. \& Taylor, J. Amplification and Direct Sequencing of Fungal Ribosomal RNA Genes for Phylogenetics. PCR Protocols: a Guide to Methods and Applications (ed. Innis, M.) (Academic, 1990)

42. Moreno-Hagelsieb, G. \& Latimer, K. Choosing BLAST options for better detection of orthologs as reciprocal best hits. Bioinformatics 24, 319-324 (2008).

43. Raina, J. B., Tapiolas, D., Willis, B. L. \& Bourne, D. G. Coral-associated bacteria and their role in the biogeochemical cycling of sulfur. Appl. Environ. Microbiol. 75, 3492-3501 (2009).

44. González, J. M. et al. Bacterial community structure associated with a dimethylsulfoniopropionate-producing North Atlantic algal bloom. Appl. Environ. Microbiol. 66, 4237-4246 (2000).

45. Todd, J. D. etal. DddQ, a novel, cupin-containing, dimethylsulfoniopropionatelyase in marine roseobacters and in uncultured marine bacteria. Environ. Microbiol. 13, 427-438 (2010).

46. Todd, J. D. et al. Structural and regulatory genes required to make the gas dimethylsulfide in bacteria. Science 315, 666-669 (2007)

47. Gómez-Consarnau, L., Lindh, M. V., Gasol, J. M. \& Pinhassi, J. Structuring of bacterioplankton communities by specific dissolved organic carbon compounds. Environ. Microbiol. 14, 2361-2378 (2012).

48. Curson, A. R. J., Rogers, R., Todd, J. D., Brearley, C. A. \& Johnston, A. W. B. Molecular genetic analysis of a dimethylsulfoniopropionatelyase that liberates the climatechanging gas dimethylsulfide in several marine $\alpha$-proteobacteria and Rhodobacter sphaeroides. Environ. Microbiol. 10, 757-767 (2008).

49. Todd, J. D., Curson, A. R. J., Nicholson, P. \& Johnston, A. W. B. The dddP gene, encoding a novel enzyme that converts dimethylsulfoniopropionate into dimethyl sulfide, is widespread in ocean metagenomes and marine bacteria and also occurs in some Ascomycete fungi. Environ. Microbiol. 11, 1376-1385 (2009).

50. Howard, E. C. et al. Bacterial taxa that limit sulfur flux from the ocean. Science $\mathbf{3 1 4}$, 649-652 (2006).

51. Schäfer, H. Isolation of Methylophaga spp. from marine dimethylsulfide degrading enrichment cultures and identification of polypeptides induced during growth on dimethylsulfide. Appl. Environ. Microbiol. 73, 2580-2591 (2007).

52. Vogt, C. \& Fischer, U. Influence of reduced inorganic sulfur compounds and oxygen on DMS oxidation and DMS reduction by the marine purple "nonsulfur" bacterium Rhodovulum sulfidophilum strain W4. Microbiol. Res. 153, 219-226 (1998) 

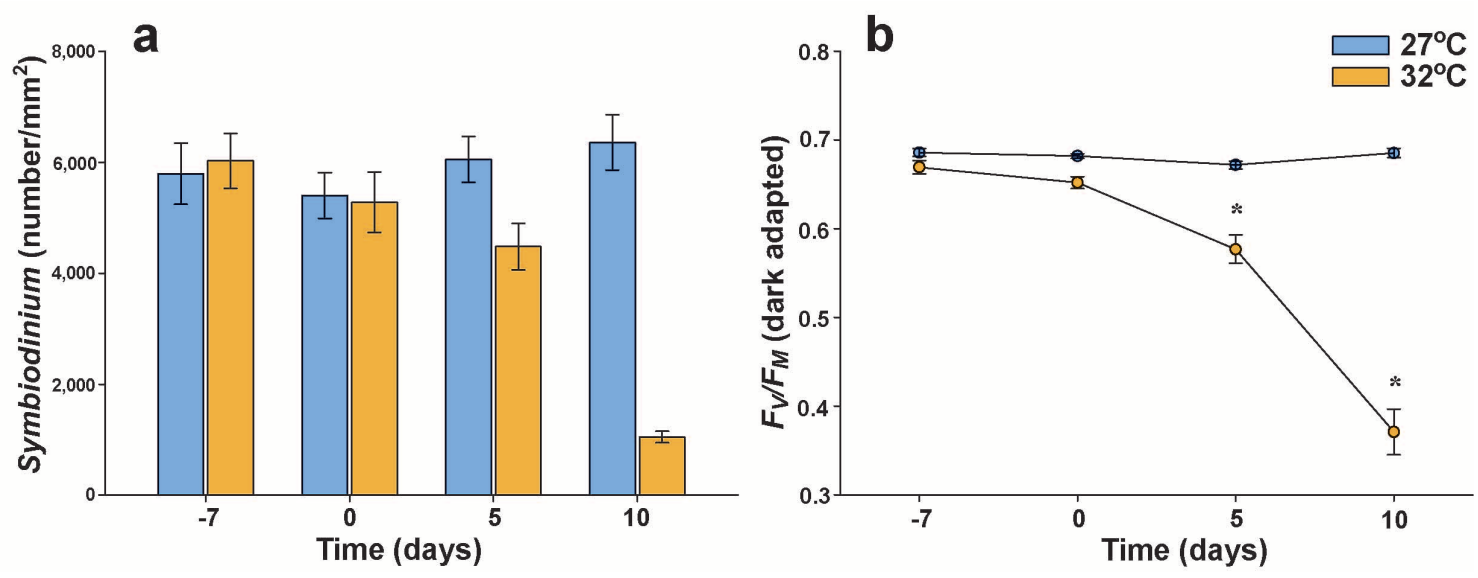

Extended Data Figure $1 \mid$ Density and photosynthetic efficiency

coral fragments through time. b, Comparison of photosystem II photochemical (mean \pm s.e.) of Symbiodinium cells within adult colonies of the coral Acropora millepora maintained under control $\left(27^{\circ} \mathrm{C}\right)$ or thermal stress $\left(32{ }^{\circ} \mathrm{C}\right)$ conditions for 10 days. a, Density of Symbiodinium cells in the same efficiency (maximum quantum yields: $F_{\mathrm{V}} / F_{\mathrm{M}}$ ) through time (repeated measure ANOVA, ${ }^{*} P<0.001$; post-hoc simple main effect test, $\left.{ }^{*} P<0.01\right)$. See also Extended Data Table 3. 

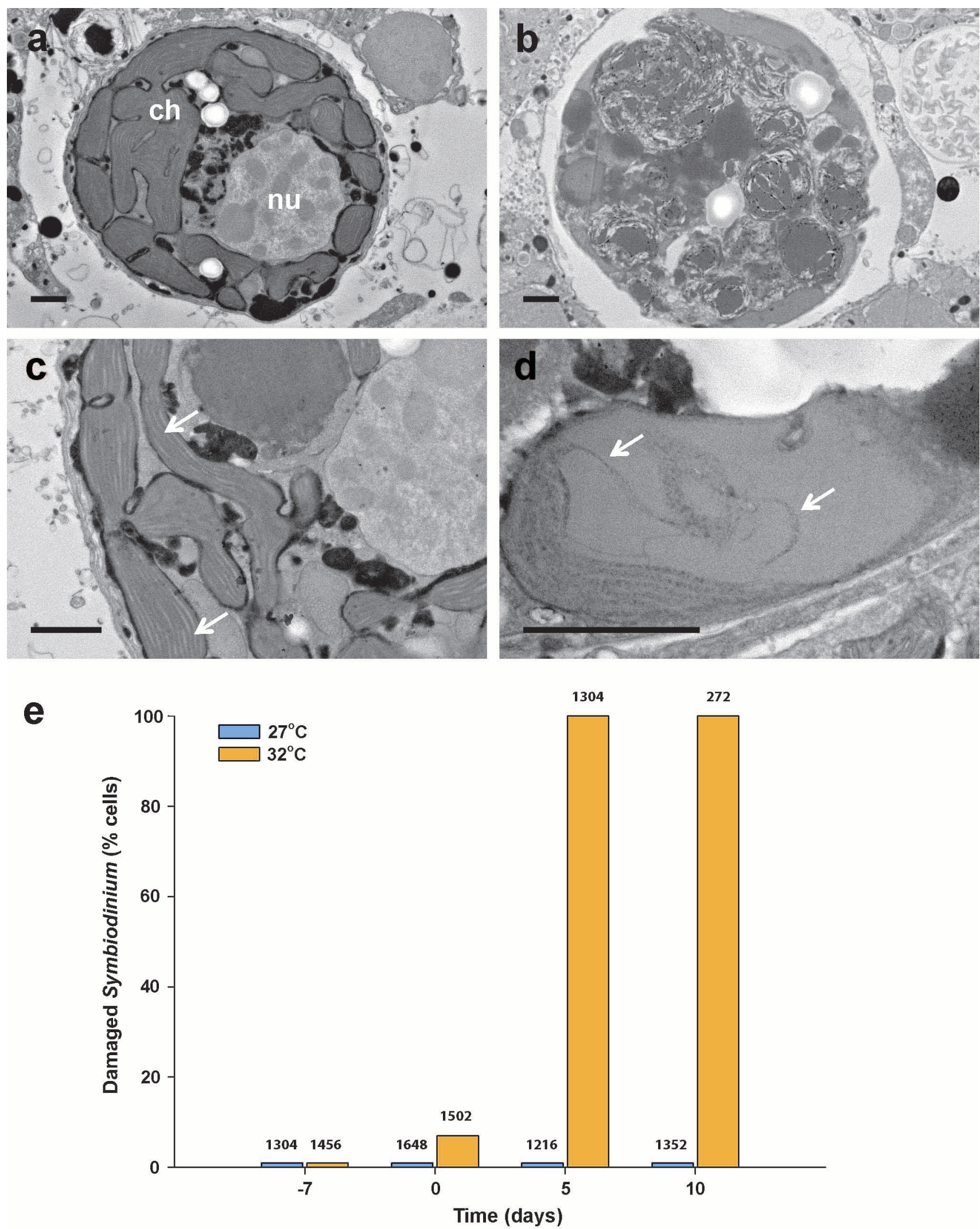

Extended Data Figure $2 \mid$ Representative transmission electron micrographs showing the effects of thermal stress on the internal structure of endosymbiotic Symbiodinium cells associated with the coral Acropora millepora. a, c, Symbiodinium cells after 10 days at $27^{\circ} \mathrm{C}$, showing intact cell structures (a) and intact thylakoid membranes of chloroplasts (arrows), the photosynthetic centre of cells (c). b, d, Symbiodinium cells after 10 days at
$32{ }^{\circ} \mathrm{C}$, showing structurally degraded cells (b) with highly disrupted thylakoid membranes (arrows) (d). Scale bars, $1 \mu \mathrm{m}$. ch, chloroplast; nu, nucleus. e, Percentage of structurally damaged Symbiodinium cells within adult tissue throughout the thermal stress experiment. The numbers above the bars refer to the total number of Symbiodinium cells observed. 


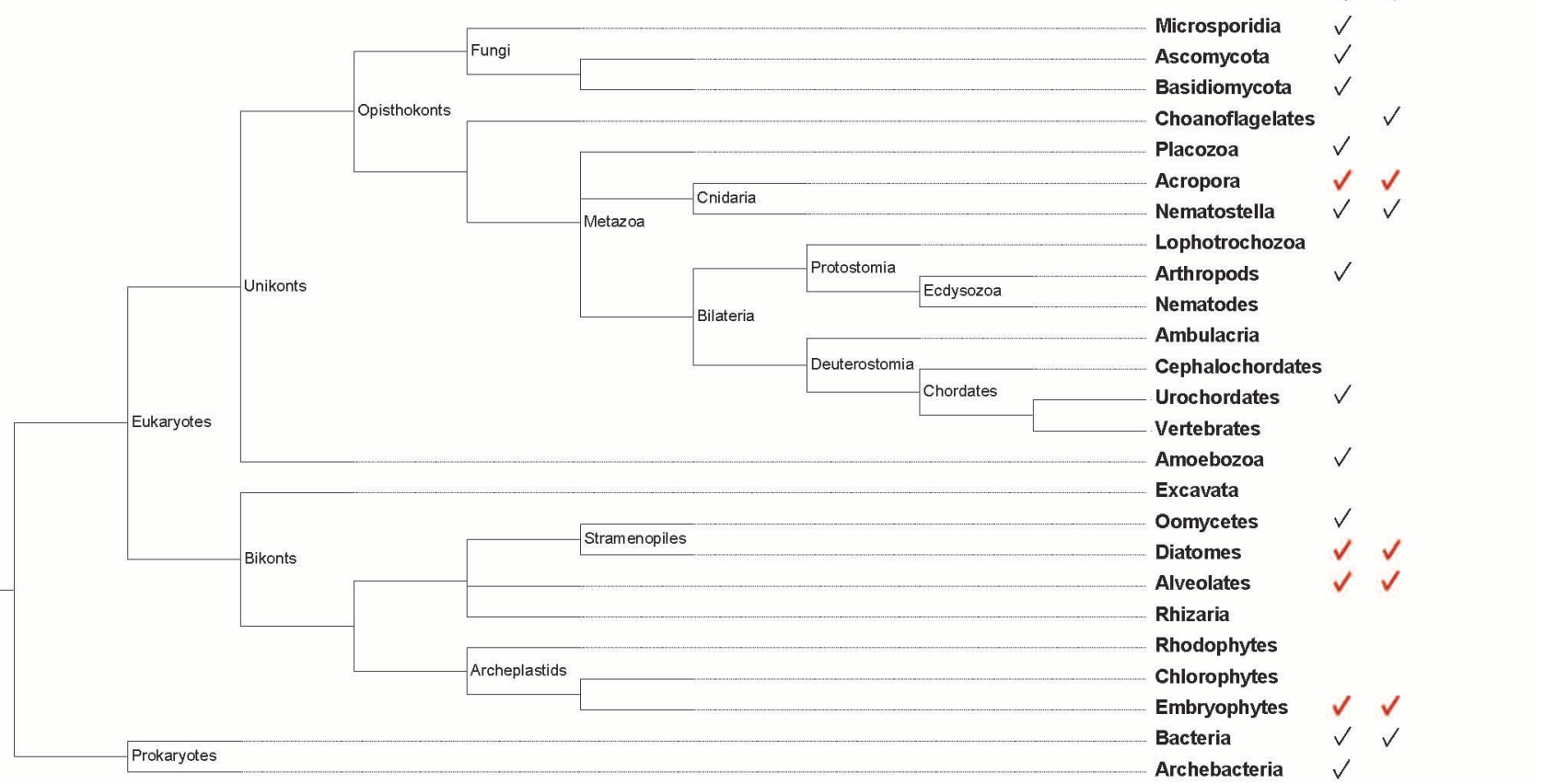

Extended Data Figure $3 \mid$ Phylogenetic distribution of the reductase and methyltransferase orthologues (OrthoMCL groups OG5_131390 and OG5_156314, respectively). Note the unusually sparse distribution of OG5_156314. In red: co-occurrence of these two enzymes occurs predominantly in DMSP-producing organisms. The only species of bacteria in the OrthoMCL database where these two enzymes occur simultaneously is the marine cyanobacterium Synechococcus. 


\section{RESEARCH LETTER}

Extended Data Table 1 | Primer pairs used to target the genomic DNA of various microorganisms possibly responsible for DMSP production to assess presence in coral juveniles

\begin{tabular}{|c|c|c|c|c|c|c|c|}
\hline $\begin{array}{c}\text { Target } \\
\text { organisms }\end{array}$ & $\begin{array}{l}\text { Target } \\
\text { region }\end{array}$ & Primer name & Amplicon size & $\begin{array}{c}\text { Annealing } \\
\text { temperature }\end{array}$ & $\begin{array}{c}\text { Number of } \\
\text { cycles }\end{array}$ & Reference & Amplification \\
\hline Coral & mtDNA & RNS2/GR & $700 \mathrm{bp}$ & $54^{\circ} \mathrm{C}$ & 30 & 36 & Yes \\
\hline Symbiodinium & ITS1 & ITSFP/ITSRP & $350 \mathrm{bp}$ & $59^{\circ} \mathrm{C}$ & 30 & 31 & No \\
\hline Algae & $\begin{array}{l}\text { 23S rDNA } \\
\text { plastid }\end{array}$ & $\mathrm{p} 23 \mathrm{SrVfl} / \mathrm{Vr} 1$ & $410 b p$ & $\begin{array}{l}\text { Touchdown PCR } \\
\left(66 \text { to } 58^{\circ} \mathrm{C}\right)\end{array}$ & 35 & 37 & No \\
\hline $\begin{array}{l}\text { Photosynthetic } \\
\text { organisms }\end{array}$ & cpDNA & $\mathrm{a} / \mathrm{b}$ & Variable & $55^{\circ} \mathrm{C}$ & 35 & 38 & No \\
\hline $\begin{array}{c}\text { Photosynthetic } \\
\text { organisms }\end{array}$ & cpDNA & $\mathrm{c} / \mathrm{d}$ & Variable & $55^{\circ} \mathrm{C}$ & 35 & 38 & No \\
\hline $\begin{array}{c}\text { Photosynthetic } \\
\text { organisms }\end{array}$ & cpDNA & $e / f$ & Variable & $55^{\circ} \mathrm{C}$ & 35 & 38 & No \\
\hline Bacteria & 16S rRNA & $63 f / 1387 r$ & $1300 \mathrm{bp}$ & $55^{\circ} \mathrm{C}$ & 30 & 39 & Yes \\
\hline Fungi & ITS1 & ITS1f/ITS4 & Variable & $55^{\circ} \mathrm{C}$ & 30 & 41 & No \\
\hline Archaea & 16 rRNA & $349 \mathrm{f} / 806 \mathrm{r}$ & $457 \mathrm{bp}$ & $59^{\circ} \mathrm{C}$ & 30 & 40 & No \\
\hline
\end{tabular}

mtDNA, mitochondrial DNA; cpDNA, chloroplast DNA; ITS, internal transcribed spacer; bp, base pairs. 
Extended Data Table 2 | Sums of squares (SS), mean squares (MS) and significance levels for ANOVAs of the Symbiodinium-free juvenile experiment

a

DMSP in Acropora millepora

\begin{tabular}{|c|c|c|c|c|c|}
\hline Effect & SS & $\mathrm{df}$ & MS & $\mathrm{F}$ & $p$ \\
\hline Intercept & 132.6612 & 1 & 132.6612 & 6959.515 & 0.000000 \\
\hline Temperature & 0.8075 & 1 & 0.8075 & 42.3610 & 0.000068 \\
\hline Time 2 & 0.0788 & 1 & 0.0788 & 4.1343 & 0.069420 \\
\hline Time 4 & 0.3015 & 1 & 0.3015 & 15.8185 & 0.002612 \\
\hline Time 6 & 0.5277 & 1 & 0.5277 & 27.6862 & 0.000367 \\
\hline Error & 0.1906 & 10 & 0.0191 & & \\
\hline Time & 1.2373 & 2 & 0.6186 & 24.7230 & 0.000004 \\
\hline Time $\times$ Temperature & 0.1007 & 2 & 0.0504 & 2.0120 & 0.159840 \\
\hline $27^{\circ} \mathrm{C}$ & 0.3160 & 2 & 0.1580 & 6.3099 & 0.007500 \\
\hline $32^{\circ} \mathrm{C}$ & 1.0220 & 2 & 0.5110 & 20.4073 & 0.000015 \\
\hline Error & 0.5005 & 20 & 0.0250 & & \\
\hline
\end{tabular}

DMSP in Acropora tenuis

\begin{tabular}{|c|c|c|c|c|c|c|}
\hline \multicolumn{2}{|l|}{ Effect } & $\mathrm{SS}$ & $\mathrm{df}$ & MS & $\mathrm{F}$ & $p$ \\
\hline \multicolumn{2}{|l|}{ Intercept } & 162.4001 & 1 & 162.4001 & 6250.471 & 0.000000 \\
\hline \multicolumn{2}{|l|}{ Temperature } & 0.5032 & 1 & 0.5032 & 19.368 & 0.001333 \\
\hline & Time 2 & 0.0858 & 1 & 0.0858 & 3.3033 & 0.099181 \\
\hline & Time 4 & 0.1720 & 1 & 0.1720 & 6.6189 & 0.027760 \\
\hline & Time 6 & 0.2715 & 1 & 0.2715 & 10.4499 & 0.008981 \\
\hline \multicolumn{2}{|l|}{ Error } & 0.2598 & 10 & 0.0260 & & \\
\hline \multicolumn{2}{|c|}{ Time } & 1.5042 & 2 & 0.7521 & 19.8690 & 0.000018 \\
\hline \multicolumn{2}{|c|}{ Time $\mathrm{x}$ Temperature } & 0.0261 & 2 & 0.0130 & 0.3440 & 0.712926 \\
\hline & $27^{\circ} \mathrm{C}$ & 0.5677 & 2 & 0.2839 & 7.5112 & 0.003688 \\
\hline & $32^{\circ} \mathrm{C}$ & 0.9625 & 2 & 0.4812 & 12.7343 & 0.000271 \\
\hline Error & & 0.7571 & 20 & 0.0378 & & \\
\hline
\end{tabular}

b Acrylate in Acropora millepora

\begin{tabular}{|c|c|c|c|c|c|c|}
\hline Effect & & SS & df & MS & $\mathrm{F}$ & $p$ \\
\hline Intercept & & 230.3004 & 1 & 230.3004 & 1830.657 & 0.000000 \\
\hline \multirow{4}{*}{ Temperature } & & 0.3525 & 1 & 0.3525 & 2.8020 & 0.125088 \\
\hline & Time 2 & 0.0433 & 1 & 0.0433 & 0.3442 & 0.570427 \\
\hline & Time 4 & 0.1583 & 1 & 0.1583 & 1.2583 & 0.288179 \\
\hline & Time 6 & 0.7030 & 1 & 0.7030 & 5.5882 & 0.039685 \\
\hline Error & & 1.2580 & 10 & 0.1258 & & \\
\hline Time & & 0.4889 & 2 & 0.2444 & 5.4270 & 0.013110 \\
\hline Time $\times$ Tempe & erature & 0.5521 & 2 & 0.2760 & 6.1290 & 0.008394 \\
\hline & $27^{\circ} \mathrm{C}$ & 0.0010 & 2 & 0.0005 & 0.0111 & 0.988964 \\
\hline & $32^{\circ} \mathrm{C}$ & 1.0400 & 2 & 0.5200 & 11.5479 & 0.000463 \\
\hline Error & & 0.9008 & 20 & 0.0450 & & \\
\hline
\end{tabular}

Acrylate in Acropora tenuis

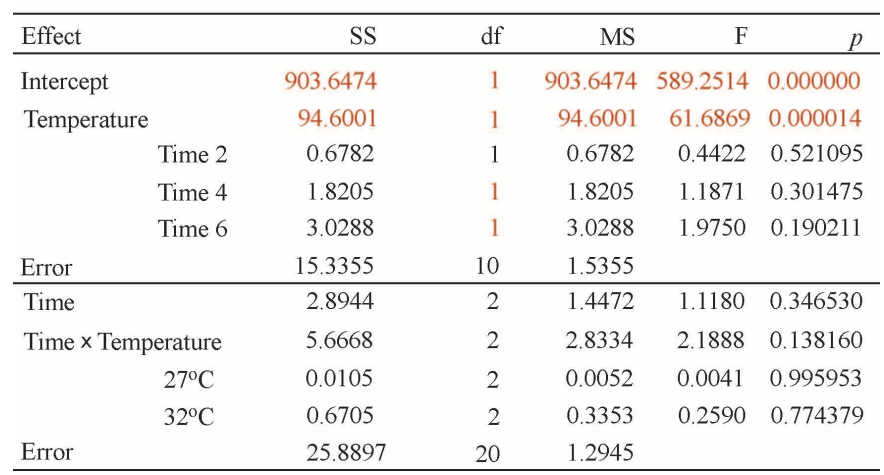

DMSP concentrations (a) and acrylate concentrations (b) are shown. Red lines show significant differences $(P<0.05)$. 
Extended Data Table 3 | Sums of square (SS), mean squares (MS) and significance levels for ANOVAs of the thermal stress experiment on adult Acropora millepora corals

\begin{tabular}{|c|c|c|c|c|c|}
\hline & SS & df & MS & $\mathrm{F}$ & $p$ \\
\hline & 1308.7770 & 1 & 1308.7770 & 2314.789 & 0.000000 \\
\hline & 11.0560 & 1 & 11.0560 & 19.5550 & 0.000215 \\
\hline Time -7 & 0.0105 & 1 & 0.0105 & 0.0186 & 0.893047 \\
\hline Time 0 & 1.9423 & 1 & 1.9423 & 3.4377 & 0.077184 \\
\hline Time 5 & 6.1001 & 1 & 6.1001 & 10.7966 & 0.003374 \\
\hline Time 10 & 7.2047 & 1 & 7.2047 & 12.7517 & 0.001707 \\
\hline & 12.4390 & 22 & 0.5650 & & \\
\hline & 8.7870 & 3 & 2.9290 & 11.2720 & 0.000005 \\
\hline erature & 4.2010 & 3 & 1.4000 & 5.3890 & 0.002226 \\
\hline $27^{\circ} \mathrm{C}$ & 1.5627 & 3 & 0.5209 & 2.0035 & 0.122017 \\
\hline $32^{\circ} \mathrm{C}$ & 11.4258 & 3 & 3.8086 & 14.6485 & 0.000000 \\
\hline & 17.1510 & 66 & 0.2600 & & \\
\hline
\end{tabular}

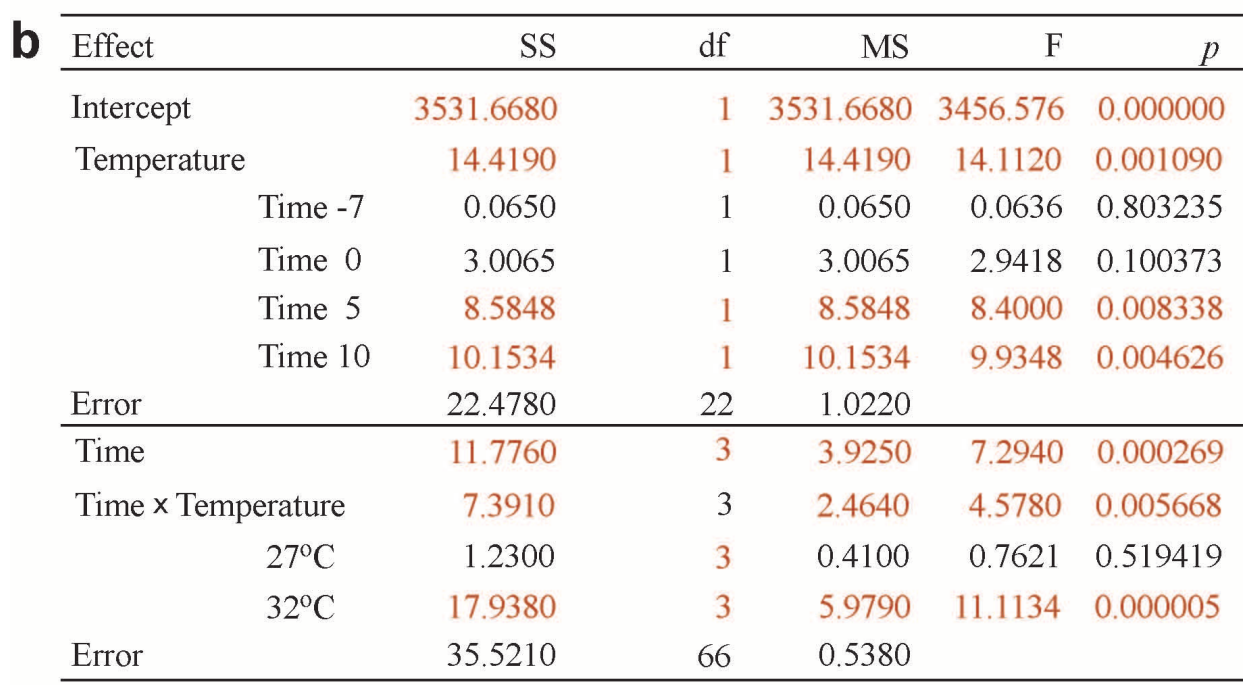

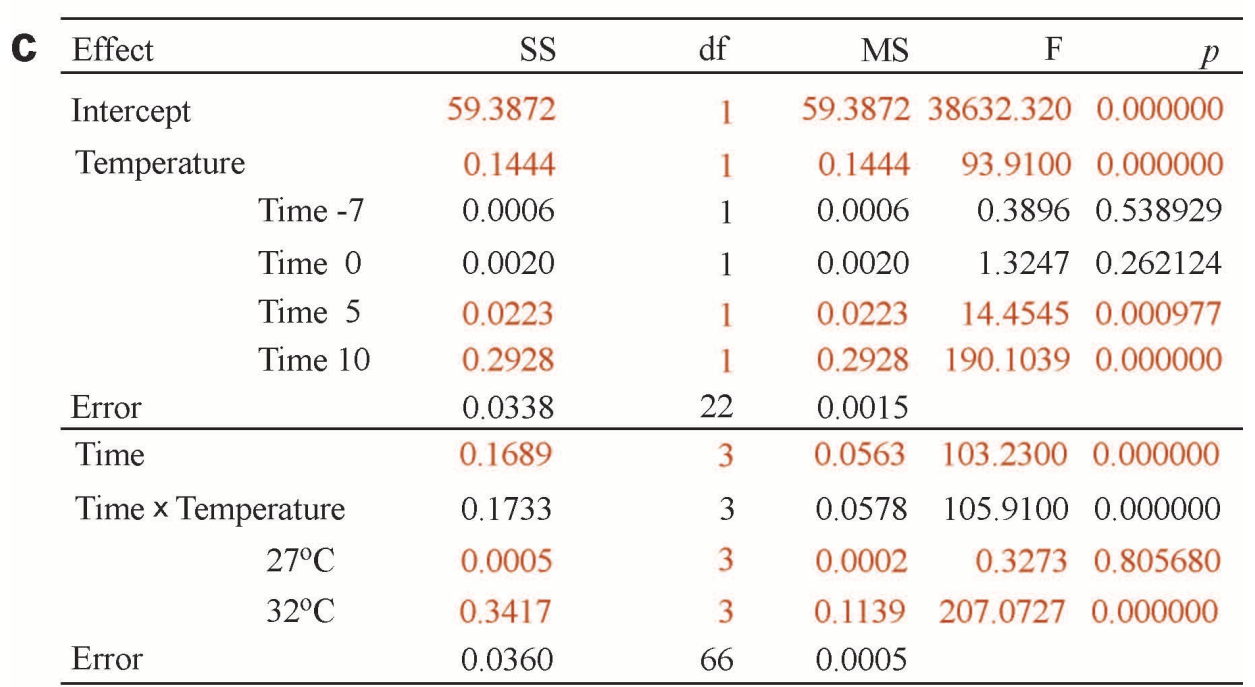


Extended Data Table 4 | Description of the reductase and methyltransferase sequences in diatoms, corals and Symbiodinium

\begin{tabular}{lcc}
\hline & Reductase & Methyltransferase \\
\hline Fragilariopsis cylindmis & jgi|Fracy1|173405|estExt & jgi|Fracy 1|207357|estExt \\
_Genewise1.C_220021 & _Genewise1Plus.C_41074 \\
Acropora digitifera & adi_v1.10730 & adi_v1.21031 \\
Acropora millepora & Cluster027405 & Cluster022229 \\
Symbiodinium (clade A, strain k8) & kb8_c41244 & kb8_rep_c2522 \\
Pfam domain & FMN_red (PF03358.8) & Methyltransf_7 (PF03492.8) \\
OrthoMCL cluster & OG5_131390 & OG5_156314 \\
\hline
\end{tabular}




\section{RESEARCH LETTER}

Extended Data Table 5 | Composition of coral juvenile bacterial communities present in the two different coral species at the two temperature regimes after 6 days

\begin{tabular}{|c|c|c|c|c|c|c|}
\hline Genus & $\begin{array}{l}\text { A. tenuis } \\
27^{\circ} \mathrm{C} \\
\end{array}$ & $\begin{array}{l}\text { A. tenuis } \\
32^{\circ} \mathrm{C}\end{array}$ & $\begin{array}{l}\text { A. millepora } \\
27^{\circ} \mathrm{C} \\
\end{array}$ & $\begin{array}{l}\text { A. millepora } \\
32^{\circ} \mathrm{C} \\
\end{array}$ & $\begin{array}{c}\text { DMSP } \\
\text { degradation }\end{array}$ & $\begin{array}{c}\text { DMS } \\
\text { degradation }\end{array}$ \\
\hline Alteromonas & & 16.7 & 6.3 & 2.1 & 43 & \\
\hline Endozoicomonas & & & 8.3 & 10.4 & 43 & \\
\hline Hyphomonas & 4.2 & & 2.1 & 2.1 & 44 & \\
\hline Idiomarina & 2.1 & & & & 43 & \\
\hline Labrenzia & & & & 4.2 & 45 & \\
\hline Marinomonas & & 2.1 & & 4.2 & 46 & \\
\hline Neptuniibacter & 22.9 & 4.2 & 8.3 & 2.1 & 47 & \\
\hline Oceanicola & & 2.1 & 2.1 & 2.1 & 48 & \\
\hline Phaeobacter & 22.9 & 4.2 & 12.5 & 6.3 & 49 & \\
\hline Pseudoalteromonas & & & 2.1 & & 44 & \\
\hline Ruegeria & 25.0 & 29.2 & 33.3 & 20.8 & 50 & \\
\hline Sagittula & & & & 2.1 & 46 & \\
\hline Stappia & & & & 2.1 & 48 & \\
\hline Methylophaga & 2.1 & & & & & 51 \\
\hline Rhodovulum & & 12.5 & 10.4 & 25.0 & & 52 \\
\hline Bdellovibrio & 2.1 & & & & & \\
\hline Hellea & 2.1 & & & & & \\
\hline Krokinobacter & 2.1 & & & & & \\
\hline Lacinutrix & 2.1 & & & & & \\
\hline Maricaulis & 2.1 & & 2.1 & & & \\
\hline Mesorhizobium & & & & 4.2 & & \\
\hline Methylosinus & 2.1 & & & & & \\
\hline Planifilum & & & 2.1 & & & \\
\hline Ponticaulis & 2.1 & 10.4 & 2.1 & 4.2 & & \\
\hline Pseudovibrio & & 2.4 & & & & \\
\hline Ralstonia & 2.1 & & & 2.1 & & \\
\hline Shimia & & 6.3 & 4.2 & 4.2 & & \\
\hline Simiduia & & 2.1 & & & & \\
\hline Spongiibacter & 4.2 & 4.2 & 2.1 & 2.1 & & \\
\hline Thalassospira & & 4.2 & 2.1 & & & \\
\hline
\end{tabular}

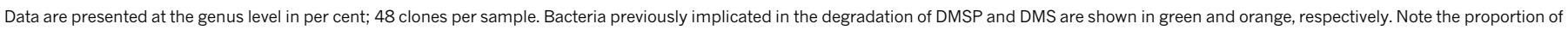
bacteria involved in DMS $(P)$ degradation, representing $79.7 \%$ of the bacteria sequenced. References ${ }^{43-52}$ are cited in this table. 